\title{
Synthetic Cannabinoid Measurement
}

National Cancer Institute

\section{Source}

National Cancer Institute. Synthetic Cannabinoid Measurement. NCI Thesaurus. Code C135402.

The determination of the amount of synthetic cannabinoids present in a biological sample. 